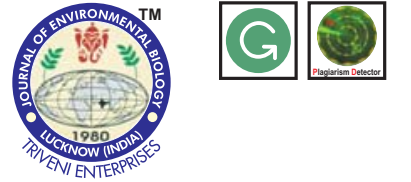

DOI : http://doi.org/10.22438/jeb/38/4/MRN-366

\title{
Prevalence of extended-spectrum $\beta$-lactamase producing Escherichia coli in seafood from the retail fishery outlets of Veraval, Gujarat, India
}

Authors Info

G.K. Sivaraman ${ }^{1 *}$, M.M. Prasad², A.K. Jha', S. Visnuvinayagam ${ }^{3}$, V. Renuka', S. Remya', Y. Kriplani ${ }^{1}$ and D. Vanik

${ }^{1}$ ICAR-Veraval Research Centre of Central Institute of Fisheries Technology, Veraval- 362 269, India

${ }^{2}$ Microbiology, Fermentation and Biotechnology Division, ICARCentre of Institute of Fisheries Technology, Cochin- 682 029, India

${ }^{3}$ ICAR- Mumbai Research Centre of Institute of Fisheries Technology, Navi Mumbai- 400703 , India

${ }^{*}$ Corresponding Author Email : gkshivraman@gmail.co

Key words

Antibiotic resistance, Beta-lactamase, Escherichia coli, Multi drug resistance, Seafood

Publication Info

Paper received : 26.05 .2016

Revised received: 30.07 .2016 Re-revised received : 09.11.2016 Accepted: 16.12 .2016
Abstract

Aim: Profound and unregulated utilization of beta-lactam antibiotics for the treatment of various infections has lead to various bacteria being resistant against these antibiotics. $E$. coli is well known to produce extended, spectrum $\beta$-lactamase (ESBL) type of $\beta$-lactamase, which has the ability to hydrolyse the entire group of $\beta$-lactam antibiotics. Currently, reports on the occurrence of ESBL producing $E$. coli in seafood is meagre. Therefore, the objective of this study was to monitor the prevalence of multiple drug resistant (MDR) and ESBL producing E. coli in seafood in Veraval region of Gujarat.

Methodology: Identification and isolation of $E$. coli was carried out using ISO, 9308-1 method with minor modification. A $0.5 \mathrm{ml}$ of serially diluted fish sample was spread on Tergitol-7 media (Oxoid, CM0793) and incubated at $35^{\circ} \mathrm{C}$ for $24 \mathrm{hrs}$. Typical flat, dry and yellow colonies with or without red tinge were further streaked on EMB plates and then subjected to IMViC and 20E BioMerieux identification kit. All the confirmed $E$. coli isolates were subjected to antimicrobial susceptibility testing, and Minimum Inhibitory Concentration (MIC) was determined.

Results: A total of 28 number of $E$. coli (approx 12\%) isolates were identified from 238 fish samples. All these isolates were subjected to antimicrobial susceptibility testing and a higher rate of resistance was found with ampicillin (39.29\%), trimethoprim/ sulfamethoxizole (32.14\%), ciprofloxacin (28.57\%) cefepime $(17.86 \%)$ and cefuroxime $(17.86 \%)$. All these isolates were sensitive to carbapenems and beta-lactam, beta-lactam inhibitors and aminoglucosides. Out of total 28, E. coli isolated $(15.71 \%)$ eleven isolates were found to be multidrug resistant and four (14.29\%) isolates were ESBL producers.

Interpretation: This study confirms the presence of hazardous MDR and ESBL producing $E$. coli in fish and fishery products in Veraval, Gujarat.

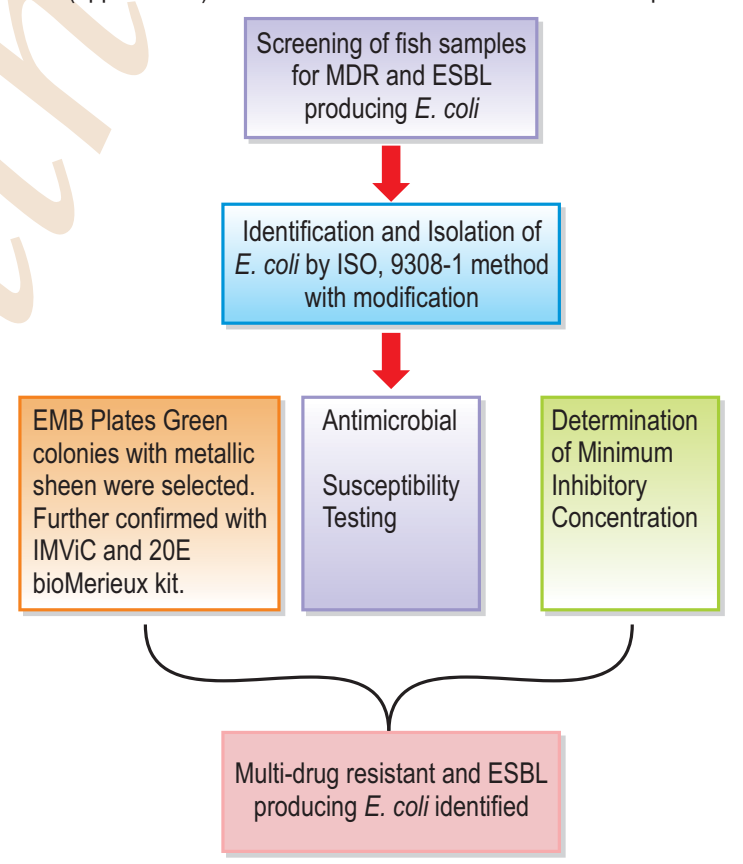




\section{Introduction}

Beta-lactam antibiotics are most by preferred for the treatment of various infectious diseases in human therapies, farm animals and aquaculture now a days. $\beta$ - Lactamase is an enzyme produced by particular type of bacteria to counterattack the $\beta$ lactam antibiotics. The term Extended Spectrum $\beta$-lactamase (ESBL) refers to a special type of $\beta$-lactamase, which can hydrolyse the entire group of $\beta$ - lactam antibiotics starting from narrow spectrum to broad spectrum. The widespread and indiscriminate use of antibiotics coupled with transmissibility of resistance leads to the emergence new ESBL producing $E$. coli (Cantos et al., 2016). A person infected with ESBL producing $E$. coli is difficult to treat (Bradford, 2001). Since, E. coli are the most common commensal bacteria existing in human and animal intestinal tract; it can become opportunistic and obligate pathogens when coexists with pathogenic strains (Bush and Jacoby, 2010). E.coli strains that produce ESBL are also becoming Multi drug resistant (MDR) and are considered to be one of the emerging pathogens worldwide (Cheng et al., 2014). Recently, ESBL producing $E$. coli have been reported in most of the food product such as meat, chicken, raw milk, fish and food products (CLSi, 2006; Egea et al., 2012; FSSAI, 2012; Elhadi and Alsamman, 2015). But, scanty reports are available regarding the occurrence of $E$. coli in seafood. Since, there is no data available about ESBL-producing bacteria in food and aquaculture products and food of animal's origin in Gujarat, the present study was carried out to monitor the presence of multiple drug resistant (MDR) and ESBL producing E. coli in seafood sampled during 2011 to 2015 from retail fishery outlets in Veraval, Gujarat, India.

\section{Materials and Methods}

Sample collection : A total of 238 fish samples consisting of Pomfret (4), Horse Mackerel (19), Indian Mackerel (18), Tuna (05), Ribbon fish (32), Seer fish (08), Croaker (19), Ghol (05), Dhoma (11), Sardine (06), Prawns (19), Shark (4), Ray fish (5), Dried fishes (23), cuttle fishes (29), cephalopods (18) and surimi (13) were collected from retail fishery outlets in and around Veraval region (Gujarat) and brought to laboratory immediately replace with in suitable sterile polythene bags for enumeration of E. coli.

Enumeration and identification of $E$. coli: For enumeration of E. coli was carried out by ISO, 9308-1, 2014 method with slight modification i.e., $0.5 \mathrm{ml}$ from the serially diluted fish sample is transferred into Modified Tergitol-7 (Oxoid, CM0793) plates supplemented with $0.25 \mathrm{ml}$ of $1 \%$ Triphenyl Tetrazolium Chloride (Himedia, FD057) and spread over the surface; then, all the plates were incubated at $35^{\circ} \mathrm{C}$ for $24 \mathrm{hrs}$. Flat dry yellow colonies with or without red tinge were further streaked over Eosin Methylene Blue (EMB) agar plates; after incubation, colonies showing greenish metallic sheen were further subjected IMViC test(Montenegro et al., 1990).
Antibiotic patterns of the isolates: Twenty four antimicrobial agents were tested by disk diffusion method (Kang et al., 2005) on MuKeller-Hinton agar (MHA) in accordance with CLSI guidelines (Koo and Woo, 2011) of antimicrobial concentration and the detailed procedure given by Sivaraman et al., 2016. Around 0.5 Mc Farland concentration cultures of the isolate were taken in a sterile cotton swab and smeared over $200 \mathrm{~mm}$ (Himedia, Mumbai) size petri plates already filled with MHA. Then the readymade antibiotics disc Dodecca Enterobacteriaceae- 1 (\# DE053,

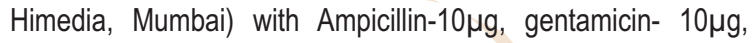
amikacin-30 $\mu \mathrm{g}$, ciprofloxacin- $5 \mu \mathrm{g}$, ofloxacin-5 $\mu \mathrm{g}$, Co-

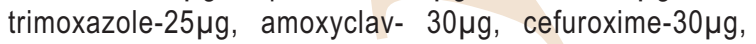
ceftazidime-30 $\mu \mathrm{g}$, ceftazidime/clavulanic acid $30 / 10 \mu \mathrm{g}$,

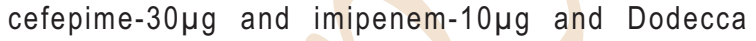

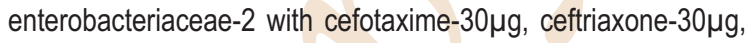

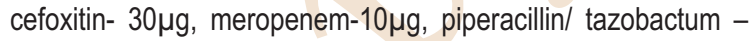

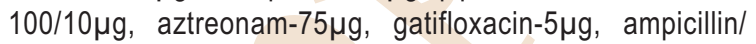
sulbactum- $10 / 10 \mu \mathrm{g}$, cefoperazone- $75 \mu \mathrm{g}$, levofloxacin- $5 \mu \mathrm{g}$, ceftizoxime- $30 \mu \mathrm{g}$ and ticarcillin/ clavulanic acid- 75/ 10 $\mathrm{\mu g}$ (\#DE054, Himedia, Mumbai) was kept over the surface and incubated for $16-24 \mathrm{hrs}$ in inverted position for the antibacterial activity.

Minimum Inhibitory concentration (MIC) : $E$. coli isolate was cultured in Brain heart infusion (BHI) broth and the concentration was adjusted to $0.5 \mathrm{Mc}$ Farland, then culture was spread over the preset MHA plates. A MIC detection strip, ESBL and AmpC detection Ezy MIC (\#079, Himedia) was placed over the agar. The MIC strip was coated with a mixture of three different antibiotics with and without clavulanic acid on a single strip in a concentration gradient manner. The upper half had Ceftazidime, Cefotaxime and Cefepime (mixture) with highest concentration of clavulanic acid tapering downwards, whereas lower half was similarly coated with Ceftazidime, Cefotaxime and Cefepime (mixture) in a concentration gradient in reverse direction.

\section{Results and Discussion}

Out of total 238 fish samples collected, 28 fish samples such as Horse Mackerel (1), Indian Mackerel (2), Ribbon fish (4), Croaker (2), Prawns (4), Dried fish (8), and surmi (7) harboured higher than recommended level of $E$. coli. Food Safety Standard Authority of India has recommended the maximum limit of $20 \mathrm{cfu}$ $\mathrm{g}^{-1} \mathrm{E}$. coli in fresh and frozen sample. Based on the above standards, Veraval retail fishery outlets were contaminated with higher level of $E$. coli $\left(0\right.$ to $\left.2.5 \times 10^{2}\right)$. Total twenty eight number of $E$. coli isolates were randomly collected from the samples, positive for $E$. coli and tested for resistant level and ESBL production. The higher rate of resistant was found with ampicillin (39.29\%), trimethoprim/ sulfamethoxizole (32.14\%), ciprofloxacin $(28.57 \%)$ cefepime $(17.86 \%)$ and cefuroxime $(17.86 \%)$. Whereas, these isolates were susceptible to carbapenems (imipenem and meropenem), beta-lactam and beta-lactam inhibitors (piperacillin/tazobactum and ampicillin/ 
Table 1: Antibiotic resistance of E.coli isolated from the seafood

\begin{tabular}{|c|c|c|c|c|c|}
\hline Antibiotics & Antibiotic group & $\begin{array}{l}\text { No. of resistant } \\
\text { isolates }\end{array}$ & $\begin{array}{l}\% \text { of resistant } \\
\text { isolates }\end{array}$ & $\begin{array}{l}\text { No. of intermediate } \\
\text { isolates }\end{array}$ & $\begin{array}{l}\% \text { of intermediate } \\
\text { isolates }\end{array}$ \\
\hline Ceftazidime (CAZ) & Cephems & 4 & 14.29 & 1 & 3.57 \\
\hline Cefepime (CPM) & & 5 & 17.86 & 1 & 3.57 \\
\hline Cefuroxime (CXM) & & 5 & 17.86 & 1 & 3.57 \\
\hline Ceftizoxime (CZX) & & 2 & 7.14 & 1 & 3.57 \\
\hline Cefoperazone (CPZ) & & 3 & 10.71 & 2 & 7.14 \\
\hline Cefotaxime (CTX) & & 3 & 10.71 & 2 & 7.14 \\
\hline Ceftriaxone (CTR) & & 3 & 10.71 & 2 & 7.14 \\
\hline Cefoxitin (CX) & & 2 & 7.14 & 0 & 0 \\
\hline Amoxyclav (AMC) & Beta-Lactam and & 3 & 10.71 & 2 & 7.14 \\
\hline Ticarcillin/Clavulanicacid (TCC) & $\begin{array}{l}\text { Beta-Lactamase } \\
\text { Inhibitors }\end{array}$ & 2 & 7.14 & 5 & 17.86 \\
\hline Piperacillin/Tazobactum (PIT) & & 0 & 0 & 3 & 10.71 \\
\hline Ampicillin/Sulbactum (A-S) & & 0 & 0 & 3 & 10.71 \\
\hline Imipenem (IPM) & Carbapenems & 0 & 0 & 0 & 0 \\
\hline Meropenem (MRP) & & 0 & 0 & 0 & 0 \\
\hline Ofloxacin (OF) & Fluoroquinolones & 1 & 3.57 & 5 & 17.86 \\
\hline Ciprofloxacin (CIP) & & 8 & 28.57 & 2 & 7.14 \\
\hline Gatifloxacin (GAT) & & 1 & 3.57 & 2 & 7.14 \\
\hline Levofloxacin (LE) & & 0 & 0 & 0 & 0 \\
\hline Ampicillin (AMP) & Penicillin & 11 & 39.29 & 2 & 7.14 \\
\hline Trimethoprim/Sulfamethoxazole (COT) & Sulfonamides & 9 & 32.14 & 1 & 3.57 \\
\hline Amikacin (AK) & Aminoglycosides & 0 & 0 & 0 & 0 \\
\hline Gentamicin (GEN) & & 0 & 0 & 0 & 0 \\
\hline Aztrenam (AT) & Monobactum & 3 & 10.71 & 3 & 10.71 \\
\hline Ceftazidime/ Clavulanicacid (CAC) & $\begin{array}{l}\text { Cephems/Beta- } \\
\text { Lactam Inhibitor }\end{array}$ & 2 & 7.14 & 2 & 7.14 \\
\hline
\end{tabular}

sulbactum) and aminoglycosides (amikacin and gentamicin) shown in Table. 1.

In the present study, eleven (15.71\%) E. coli isolates mainly from Ribbon fish and dried fish were found to be multidrug resistant multidrug resistant (MDR). As per report, these isolates were resistant to more than three types of antibiotics and were considered as MDR isolate. The presence of hazardous nature of MDR bacteria in the fish indicates poor hygienic status of the fishery outlets.

The ESBL producing $E$. coli are more dangerous than the MDR E. coli. In the present study, four (14.29\%) of E. coli isolates out of twenty eight confirmed $E$. coli were ESBL producers. Triple ESBL detection Ezy MIC Strip was used to identify the ESBL strain. The upper half had Ceftazidime, Cefotaxime and Cefepime (Mixture) with Clavulanic acid with highest concentration tapering downwards, where as lower half was similarly coated with Ceftazidime, Cefotaxime and Cefepime (Mixture) without Clavulanic acid in a concentration gradient in reverse direction. Based on the kit protocol, it was found that four out of twenty eight isolates were ESBL producing E. coli. All the ESBL producers were further analyzed in the antibiogram with twenty four antibiotics and found that all the ESBL producers were ESBLAmp C positive, multidrug resistant and showed reduced susceptibility to ampicillin.
Numerous reports are available for the presence of ESBL producing Enterobacteriaceae in food products such as meat, chicken, raw milk and fish (CLSi, 2006; Egea et al., 2012 and Elhadi and Alsamman, 2015). The present study also supported the previous report and indicated the widespread prevalence of ESBLs and MDR E. coli in seafood of Veraval region, Gujarat. So, the fish retail market may act as a possible reservoir for multiplication and spread of bacteria from fish to handlers/ consumers that become a serious threat. ESBL enzymes carrying E. coli confer resistance to most beta-lactam antibiotics mainly of extended-spectrum cephalosporins (Ojer-Usoz et al., 2013). The ESBL genes enter and disseminate through the food chain via direct contact with humans and animals and can contribute to the spread of these strains (Ozcakar et al., 2011) Moreover, the genes responsible for enzymes are easily transfered to other enterobacterial species when encounter it (Perez et al., 2007). ESBL gene are encoded on plasmids that hydrolyze all groups of beta lactum antibiotics, including new generation group of cephalosporins mainly cefotaxime and cefriaxone (Ryu et al., 2012 and Schmid et al., 2013). E. coli strains producing ESBLs are MDR and are considered to be one of the emerging pathogen world-wide (Cheng et al., 2014). 
The presence of ESBL producing $E$. coli in the fish and fishery products may be due to post harvest contamination such as infected handlers, uncleaned vessels and repeated use of contaminated water in the fishery outlets.

\section{Acknowledgments}

Authors are thankful to the Director, ICAR- CIFT, Cochin, Kerala for providing the necessary facilities and fund to carry out this research work. We duly acknowledge the laboratory work assisted by the technical and supporting staff of the Centre.

\section{References}

Bradford, P.A.: Extended-spectrum beta-lactamases in the 21 st century: Characterization, epidemiology and detection of this important resistance threat. Clin. Microbial Rev., 14, 933-951 (2001).

Bush, K. and G.A. Jacoby: Updated functional classification oflactamases. Antimicro. Agents Chemother., 54, 969-976 (2010).

Cantos, L., K. Suer, E. Guler and T. Imir: High emergence of ESBLproducing E. coli cystitis: Time to get smarter in Cyprus. Front. Microbiol., 6, 1-7 (2016).

Cheng. G., H. Hao, S. Xie, X. Wang, M. Dai, L. Huang and L. Yuan: Antibiotic alternatives: The substitution of antibiotics in animal husbandry. Front. Microbiol., 5, 1-15 (2014).

CLSI: M100-S25 performance standards for antimicrobial susceptibility testing; Twenty-fifth informational supplement. Clinical and Laboratory Standards Institute, USA, Vol. 35 (2015).

Egea, P., L. Lopez-Cerero, E. Torres, C.M. Gomez-Sanchez, L. Serrano, M.D. Navarro Sanchez, J.B. Rodriguez and A. Pascual: Increased raw poultry meat colonization by extended spectrum betalactamase- producing Escherichia coli in the South of Spain. Int. J Food Microbiol., 159, 69-73 (2012).

Elhadi, N. and K. Alsamman: Incidence and antimicrobial susceptibility pattern of extended-spectrum- $\beta$-lactamase-producing Escherichia coli isolated from retail imported mackerel fish. Afr. J. Biotechnol., 14, 1954-1960 (2015).
FSSAI (Food Safety and Standards Authority of India): Manual of Methods of Analysis of Foods. Lab Manual-6, Govt. of India, New Delhi (2012).

Kang, HY., Y.S. Jeong and J.Y. Oh: Characterization of antimicrobial resistance and class 1 integrons found in Escherichia coli isolates from humans and animals in Korea hospital prevalence and susceptibility patterns. Rev. Infect. Dis., 10, 867-878 (2005).

Koo, H.J. and G.J. Woo: Distribution and transferability of tetracycline resistance determinants in Escherichia coli isolated from meat and meat products. Int. J. Food Microbiol., 145, 407-413 (2011).

Montenegro, M.A., M. Bulte., T. Trumpf., S. Aleksic., G. Reuter., E. Bulling and R. Helmuth: Detection and characterisation of fecal verotoxinproducing Escherichia coli from healthy cattle. J. Clin. Microbiol,, 28, 1417-1421 (1990).

Ojer-Usoz, E., D. González, A.I. Vitas, J. Leiva, I. Garcia-Jalon, A. Febles-Casquero and L. Escolano: Prevalence of extendedspectrum $\beta$-lactamase producing Enterobacteriaceae in meat products sold in Navarra, Spain. Meat. Sci., 93, 316-21(2013).

Ozcakar, Z.B., F. Yalcinkaya, A. Kavaz, G. Kadioglu, A.H. Elhan and D. Aysev: Urinary tract infections owing to ESBL-producing bacteria: Microorganisms change clinical pattern does not. Acta Paediatr., 100,61-64 (2011).

Perez, F., A. Endimiani, K.M. Hujer and R.A. Bonomo: The continuing challenge of ESBLs. Curr. Opin. Pharmacol., 7, 459-469 (2007).

Ryu, S.H., S.G. Park, S.M. Choi, Y.O. Hwang, H.J. Ham, S.U. Kim, Y.K. Lee, M.S. Kim, G.Y. Park, K.S. Kim and Y.Z. Chae: Antimicrobial resistance and resistance genes in Escherichia coli strains isolated from commercial fish and seafood. Int. J. Food Microbiol., 152, 14-18 (2012)

Schmid, A., S. Hörmansdorfer, U. Messelhäusser, A. Kasbohrer, C. Sauter-Louis and R. Mansfeld: Prevalence of extended-spectrum $\beta$ - lactamase-producing Escherichia coli on bavarian dairy and beef cattle farms. Appl. Environ. Microbiol., 79, 302730-32 (2013).

Sivaraman, G.K., S. Visnuvinayagam, A.K. Jha, V. Renuka, S. Remya and D. Vanik: Assessment of microbial quality of fish processing industrial effluent in bar-mouth at Bhidia landing site, Veraval, Gujarat, India. J. Environ. Biol., 37, 537-541 (2016). 